BULLETIN Bulletin hispanique

HISPANIQUE Université Michel de Montaigne Bordeaux

113-1 | 2011

Actes de 2 colloques

\title{
Teresa Guerra, poeta entre el Barroco y la Ilustración
}

Anne J. Cruz

\section{(2) OpenEdition}

Journals

Edición electrónica

URL: http://journals.openedition.org/bulletinhispanique/1350

DOI: 10.4000/bulletinhispanique.1350

ISSN: 1775-3821

Editor

Presses universitaires de Bordeaux

Edición impresa

Fecha de publicación: 1 junio 2011

Paginación: 297-312

ISBN: 978-2-86781-740-3

ISSN: 0007-4640

Referencia electrónica

Anne J. Cruz, « Teresa Guerra, poeta entre el Barroco y la llustración », Bulletin hispanique [En línea], 113-1 | 2011, Publicado el 01 junio 2014, consultado el 01 mayo 2019. URL : http://

journals.openedition.org/bulletinhispanique/1350; DOI : 10.4000/bulletinhispanique.1350

Tous droits réservés 


\title{
Teresa Guerra, poeta entre el Barroco y la Ilustración
}

\author{
Anne J. Cruz \\ Universidad de Miami, Florida
}

Le recueil de poésie de la poète andalouse Teresa Guerra publié à Madrid en 1725 et approuvé par le censeur de l'époque, le polygraphe Diego Torres Villaroel, apporte la preuve de l'activité littéraire des femmes dans les premières décennies du dix-huitième siècle. Ses poèmes révèlent une sensibilité libérée de l'idéologie coercitive du Baroque, et annoncent à la fois les nouvelles tendances intellectuelles et sociales du Siècle des Lumières.

El poemario de la poeta andaluza Teresa Guerra publicado en Madrid en 1725 y aprobado por el entonces censor, el poligrafo Diego de Torres Villaroel, da fe de la actividad literaria femenil a comienzos de las primeras décadas del s. XVIII. Los poemas revelan una sensibilidad liberada de la ideología opresora del Barroco, anunciando a la vez las nuevas tendencias intelectuales y sociales de la Ilustración.

The poetry collection published in Madrid in 1725 by the Andalusian poetess Teresa Guerra and approved by the censor and polygraph Diego de Torres y Villaroel, gives proof of women's literary activity in the first decades of the eighteenth century. Her poems reveal a sensibility liberated from the oppressive ideology of the Baroque that simultaneously announce the new intellectual and social tendencies of the Enlightenment.

Mots-clés: Poésie féminine espagnole - Teresa Guerra - Siècle des Lumières - Diego de Torres Villaroel.

Bulletin Hispanique, Tome 113, nº 1 - juin 2011 - p. 297 à 312. 
$\mathrm{L}$ As querellas políticas al nivel nacional efectuadas durante los primeros años del régimen del joven rey Felipe $\mathrm{V}$ debido a la guerra de sucesión terminaron por aquietarse bajo el absolutismo impuesto por el cambio dinástico. A pesar de la miseria acumulada, los últimos años de la guerra trajeron al país consecuencias económicas moderadas, lográndose bajo los Borbones un admirable progreso material y moral ${ }^{1}$. Pese a la condición inestable del monarca, el nuevo reino de Felipe $\mathrm{V}$ introduce en España un gobierno centralizado en el que se destaca el fomento de la cultura y el arte, fundándose la Real Biblioteca del Palacio y la Real Academia Española en 1714, y la Real Academia de la Historia en $1738^{2}$. Debido a las reformas políticas y económicas y la limitación del poder de la iglesia, va surgiendo una mentalidad mucho más abierta y seglar que, sin embargo, al correr del siglo llegará a escindirse en los partidos políticos de tradicionalistas y afrancesados. Del control ejercido por la iglesia contrarreformista del siglo XVII, se pasa a una larga pugna por la libertad individual y social discorde con la Inquisición, calificada por Benito Jerónimo Feijoo como amantísima «de la antigualla» ${ }^{3}$.

A comienzos del siglo, no obstante, la transición cultural del antiguo régimen al nuevo no da muestras de ser tan clara. Si bien en Francia el estilo barroco es seguido por el movimiento designado "rococó», influenciado por el gusto de Louis XV y cuya gracia e ingenio "femeninos» se basan en la despreocupación moral ${ }^{4}$, en Espańa, la continuidad del bajo barroco se evidencia principalmente en los escritos del polígrafo Diego de Torres Villarroel, una figura elusiva sobre la que tendremos más que decir. En efecto, la literatura de las primeras décadas del siglo XVIII ha sido reprochada por su poca producción y falta de sofisticación; según la crítica,

1. Para la historia de la transición entre los Austrias y Borbones, véanse Richard Herr, The Eighteenth-Century Revolution in Spain, Princeton, N.J., Princeton University Press, 1958; Antonio Domínguez Ortíz, Sociedad y estado en el siglo XVIII español, Barcelona, Ariel, 1976; John Lynch, Bourbon Spain 1700-1808, Oxford, UK., Basil Blackwell, 1989; Henry Kamen, Philip V, The King Who Reigned Twice, New Haven, CT., Yale University Press, 2001; y Antonio Ramón Peña Izquierdo, De Austrias a Borbones: España entre los siglos XVII y XVIII, Astorga, 2009.

2. Eliseo Serrano Martín, coordinador, Felipe Vy su tiempo, 2 vols., Zaragoza, Institución Fernando el Católico, 2004.

3. En carta privada, Feijóo califica de "amantísimo de la antigualla» al Inquisidor General. Benito Feijoo, Cartas eruditas y curiosas, ed. Francisco Uscanga Meinecke, Barcelona, Crítica, 2009, p. 39.

4. Para el análisis del arte de este estilo, veáse Julio Seoane Pinilla, La política moral del Rococó: Arte y cultura en los orígenes del mundo moderno, Madrid, La Balsa de la Medusa, 2000 . 
no es hasta mediados de siglo cuando comienzan a destacarse los rasgos modernos de la Ilustración ${ }^{5}$. No obstante, debemos tener en cuenta las palabras del eminente estudioso del siglo XVIII, Emilio Palacios Fernández, quien comenta la necesidad de revisar las opiniones críticas anteriores: «La poesía, sin embargo, forma parte esencial de la sociedad de esta época si juzgamos la cantidad de libros publicados, o los humildes pliegos de cordel, o las numerosas justas poéticas que por motivos varios se celebran, siguiendo la tradición del seiscientos, o las tertulias literarias que atraen a otros más nobles o más cultos. Así, en las justas poéticas en honor a San Luis Gonzaga y San Estanislao de Kostka, que se celebran en Murcia en 1727, participan ciento cincuenta poetas» ${ }^{6}$.

Son precisamente las primeras décadas del siglo XVIII las que nos interesan, ya que la poeta de la cual escribimos, doña Teresa Guerra o Teresa de Guerra, como ella firma, publica su única obra, un poemario de 137 folios, más 23 hojas, en $1725^{7}$. Escribe, pues, en los albores de la Ilustración, adelantándose por sólo un año a la publicación de la Defensa de la mujer del padre Feijoo y unos quince ańos antes de la Vida de Torres Villarroel ${ }^{8}$. Los pocos datos que de ella manejamos provienen, como en el caso de tantas escritoras, de los Apuntes para una biblioteca de escritoras españolas de Manuel Serrano y Sanz, ahora renovada y puesta al día en el banco de datos digital «Biblioteca de Escritoras Españolas» (BIESES), dirigido por la profesora Nieves Baranda Leturio ${ }^{9}$. La escritora nace en Osuna a últimos del siglo XVII y es probable que fuera hija de D. Felipe Guerra, quien estuvo al servicio de los duques de Osuna. La censura de las Obras poéticas hecha por Francisco López Bechio de Aro explica que «es la Autora Mètrica Natural de Ossuna (Universidad antigua en Espańa) passò de su Patria à enriquecer con sus Escritos la Nobilissima Cadiz». El poemario, sin embargo, se publicó en Madrid, así que es probable que viajara o que también residiera en la capital. De la fecha de su muerte no tenemos ningún indicio.

5. Iñigo Sánchez-Llama, «¿Fue moderna la literatura española del siglo XVIII?: Análisis de la evaluación decimonónica», Hispanic Review, 76.3, 2008, pp. 231-255.

6. Emilio Palacios Fernández, «La evolución de la poesía del siglo XVIII», http://www. cervantesvirtual.com/servlet/SirveObras/01361697588915403423802/p0000001.htm.

7. Obras poéticas que a diferentes assuntos ha escrito Doña Teresa Guerra, Natural de la Villa de Ossuna, y vezina de la Ciudad de Cadiz, Madrid, 1725. La página titular no menciona el editor, sólo que se vende en la Librería de Fernando Monge, «enfrente de las Gradas de S. Felipe el Real.»

8. Benito Jerónimo Feijoo y Montenegro, Defensa de la mujer: Discurso XVI del Teatro crítico. Ed. Victoria Sau, Barcelona, Icaria, 1997; Diego de Torres Villarroel, Vida, ed. Manuel María Pérez López, Madrid: Austral, 1989.

9. Los Apuntes de Serrano y Sanz sobre Teresa Guerra (pp. 472-473) pueden verse en BIESES: http://www.uned.es/bieses/ 
Así como sabemos muy poco de la vida de esta escritora, tampoco hemos localizado mayores referencias de ella por parte de los críticos. Entre las bibliografías que mencionan a Teresa Guerra, se encuentran la Bibliografía de Francisco Aguilar Piñal, la cual recoge la misma información que Serrano y Sanz, y la Breve historia feminista de la literatura española de Iris Zavala ${ }^{10}$. La Breve historia de Zavala comienza por aseverar que «la ausencia de escritoras en la Espańa del siglo XVIII, y el silencio masculino sobre el peligro que representa la mujer que sabe escribir, y que escribe para publicar, empiezan a desaparecer alrededor del 1755» (p. 316). Aclara, sin embargo, que "surgen unos pocos nombres antes de esas fechas", los de nuestra poeta y María Andrea Casamayor, "zaragozana que publica un libro de matemáticas en 1738» (p. 317). Por tratarse de época tan temprana, Palacios no incluye a Teresa Guerra en su artículo sobre las escritoras neoclásicas, aunque sí la menciona en su libro, La mujer y las letras en la España del siglo XVIII, notando que su poemario fue muy reconocido en su tiempo ${ }^{11}$. Recorriendo la bibliografía del siglo, Palacios cita a Juan Bautista Cubié, Las mujeres vindicadas de las calumnias de los hombres (1768), quien incluye a sólo dos autoras: la nuestra y María Catalina de Caso, traductora del historiador francés Charles Rollin. Sin embargo, nos dice que en el Memorial Literario de 1786 de la Marquesa de Grimaldo, se incluye a Guerra en su «Catálogo de escritoras ilustres» (La mujer y las letras, pp. 48; 67).

Al desglosar las tendencias poéticas del siglo XVIII, Palacios sitúa a nuestra poeta entre las que él llama "poetisas posbarrocas", señalando primero a las "copleras» Ana Fuentes y María de Camporredondo (La mujer $y$ las letras, p. 134) ${ }^{12}$. En seguida, nombra a Guerra como una andaluza con mayor resonancia que las anteriores, fama que para el crítico repercute en un sentimiento de inestabilidad que hace dudar a la poeta de su propio crédito. Según Palacios, «La escritura temprana de [sus] poemas, arropados por el ambiente de una tertulia gaditana, y la aceptación ciudadana como 'poetisa', nombre que utiliza habitualmente para definir su oficio, le llenan

10. Francisco Aguilar Piñal, Bibliografía de autores españoles del s. XVIII, tomo IV, Madrid, CSIC, 1981; e Iris Zavala, coordinadora, Breve historia feminista de la literatura española (en lengua castellana) IV. La literatura escrita por mujer (De la Edad Media al s. XVIII), Barcelona, Anthropos, 1997.

11. Emilio Palacios Fernández, «El Parnaso poético femenino en el siglo XVIII: escritoras neoclásicas», http://www.cervantesvirtual.com/servlet/SirveOras/scclit/02472774 212725388976613/p0000001.htm\#I_0). Véase, en cambio, del mismo autor, La mujer y las letras en la España del siglo XVIII, Madrid, Laberinto, 2002.

12. Según Serrano y Sanz, Ana de Fuentes escribió sólo un soneto; María de Camporredondo compuso su Tratado filosófico-poético-escótico, compuesto en seguidillas, publicado en Madrid, 1757. 
TERESA GUERRA, POETA ENTRE EL BARROCO Y LA ILUSTRACIÓN

de inseguridades, mostrando una continua necesidad de autojustificación» (La mujer y las letras, p. 135). La opinión de Palacios se basa en la dedicatoria de su obra:

Venciendo mi natural debida resistencia, me faltara aliento para dar a la estampa la que siendo (efecto de mis ocios) tan pequeńa Obra, es ya la mayor causa de mi fatiga, si no fuera considerando que assegura su breve compendio en manos de V.Exc. lo digno, que no pudo conferirle mi mano, por defecto del arte y el ingenio. (Obras poéticas) ${ }^{13}$

Dicha dedicatoria revela más bien su conocimiento de la convención retórica de la captatio benevolentiae, cuando no de la humilitas, ya que a quien escribe la poeta es a dońa Francisca Bibiana Pérez de Guzmán, hija del duque de Medina Sidonia y esposa de José María Téllez-Girón, VII duque de Osuna, quien fuera el hijo del superior del padre de la poeta. Afirmando su lealtad a la Casa de Osuna, se refiere a su obra humildemente: «Venciendo mi natural debida resistencia, me faltàra aliento, para dàr à la Estampa la que siendo (efecto de mis ocios) tan pequeńa Obra ...Débil fruto es de la dichosa tierra, que a Vuestra Excelencia, Señora y digno dueño aclama con que ofrecerle yo ahora aora tributo» (Obras poéticas). La joven duquesa, que en 1725 contaba con 19 años, sería conocida por su disposición a la música, desde la popular hasta las nuevas tendencias importadas de Italia: los villancicos de los estudiantes del Colegio Mayor santo Tomás de Aquino de Sevilla, por ejemplo, van dedicados a ella ${ }^{14}$. Asimismo, el entorno artístico de la Casa de Osuna ha sido reconocido recientemente en el festival de música antigua de Úbeda y Baeza celebrado en el año 2009 por Juan Pablo Fernández Cortés, quien ha transcrito y editado un libro de la música italiana dedicada a la duquesa de Osuna ${ }^{15}$. De acuerdo con el editor, la destinataria de esta recopilación fue la misma Francisca Bibiana Pérez de Guzmán, consorte desde 1721 del duque de Osuna y administradora de la Casa de Osuna desde 1733 hasta su muerte en 1748. Confirma que «esta noble dama, gran aficionada a la música y asistente habitual a los espectáculos operísticos italianos del Teatro de los Caños del Peral de Madrid, solía organizar conciertos de música

13. Teresa Guerra, Obras Poeticas, que a diferentes assuntos ha escrito Doña Teresa Guerra, Natural de la Villa de Ossuna, y vezina de la Ciudad de Cadiz. Madrid, 1725. El paratexto del libro omite la paginación.

14. Antonio Luis Morán Saus et al., Cancionero de estudiantes de la tuna: el cantar estudiantil de la Edad Media hasta el s. XX, Salamanca: Universidad de Salamanca, 2003, p. 447.

15. Juan Pablo Fernández Cortés, Libro de Cantatas y Arias italianas de la Duquesa de Osuna, Madrid, Biblioteca Nacional, M.2245, 2009. 
vocal en su casa con algunos de los cantantes italianos del elenco de dicho teatro, para los cuales pudo realizarse esta recopilación».

El patronazgo literario de la duquesa será solicitado más tarde por el polígrafo Torres Villarroel, quien en 1737 le dedica su sátira Los desahuciados del mundo y de la gloria:

Llego ahora a sacrificar a sus pies este corto volumen, que por hijo de mi fatiga es todo de V. E. mi respeto, mi trabajo, mi aplicación y las infelices remuneraciones de mi infructuoso y despreciable estudio, todo está sujeto y esclavizado a su poderoso dominio. Nada doy, nada ofrezco, porque ni la altura de mi veneración, ni lo ansioso de mis deseos pueden tributar un don propio, ni un voto libre, porque todo es deuda forzosa y sacrificio indispensable al soberano altar de V. E. Sólo ruego a su piedad que reconozca y reciba este desvelo de mi espíritu, y esta ingenuidad de mi miserable filosofía, que en uno y en otra hallará venerables ansias, recuerdos felices y agradecida esclavitud a sus honras y a su superior grandeza ${ }^{16}$.

Al comparar las dos dedicatorias, vemos que la hiperbólica de Torres Villarroel opaca en su totalidad a la de nuestra poeta. El poder que ha asumido la duquesa en el tiempo en que Torres Villarroel le ofrenda su obra es posiblemente una de las razones por las cuales la dedicatoria peca de una excesiva adulación; otra sería la socarrona ironía del autor. En todo caso, Torres Villarroel tampoco dejará de elogiar inmoderadamente la obra de Guerra en su "Aprobación», como veremos.

En cambio, el poemario de Guerra asevera que ha salido a luz sólo «a persuasiones de sus apassionados» para consagrarse a la protección de la duquesa. El paratexto incluye las siguientes aprobaciones y licencias:

1) «Aprobación de Diego de Torres Villarroel, professor de Philosophia y Mathematicas, y Substituto à la Cathedra de Astronomía en la Universidad de Salamanca» fechada el 17 de mayo de 1725;

2) «Licencia del ordinario ... El Doctor Christoval Damasio, Canónigo de la insigne Iglesia Colegial del Sacro Monte Ylipulitano Valparaíso, Extramuros de Granada, Inquisidor Ordinario y Vicario de esta Villa de Madrid»;

16. Diego de Torres Villarroel, Los desahuciados del mundo y de la gloria. Edición digital a partir de la de Libros en que están relatados diferentes quadernos physicos, médicos, astrológicos, poéticos, morales y mysticos, que años pasados dio al público en producciones pequeñas el Doctor D. Diego de Torres Villarroel. Vol. III, Salamanca, Imp. A. Villagordo y P. Ortiz Gómez, 1752. Véase en http://www.cervantesvirtual.com/ servlet/SirveObras/ 01479513100203551932268/index.htm 
3) «Censura del Licenciado Don Francisco Lopez Bechio de Aro, Abogado de los Reales Consejos»;

4) «Licencia del Consejo: Don Balthasar de San Pedro Azevedo, Secretario del Rey Nuestro Señor y de Gobierno del Consejo»;

5) «Fee de Erratas» que corresponden con su original de fecha 2 de Octubre de 1725, según el «Lic. D. Benito del Rio y Cordido, Corrector General por su Magestad».

En cuanto al prólogo del poemario, la reticencia con que Guerra se dirige al lector de su libro demuestra que la poeta está muy al corriente de las maneras evasivas empleadas por muchas autoras, quienes se proponen ser leídas por un público cuya aceptación de la escritura femenina todavía no estaba del todo asegurada:

Nunca fue mi intencion manifestar al publico lo que por tantas razones debi dar al silencio [...] Ninguna agudeza hallaràs en sus hojas, si mucha letra basta que enmendar en sus planas. No avrà, en mi concepto, viveza que te agrade, pero ni en mi estilo cosa que te equivoque. Mas si por ventura, su breve contenido, por ser de vna Muger, adequa con tu gusto, por la misma razon no puede serte grato, si no niegas la passion de nuestro sexo. Compelida, enfin, le expongo à la censura: yo protesto la fuerza, suple tu mi ignorancia. (Obras poéticas)

No será coincidencia, por tanto, que nos deje con más deseos de indagar acerca de lo que nos trata de ocultar. Entre otras preguntas que se nos ocurren al estudiar la obra de nuestra poeta, está el por qué muestra tanta reserva en publicar su obra.

Los dos poemas incluídos de Joseph Antonio Mallén intentan persuadir a la poeta que permita dar sus poesías a la estampa:

¿Puede ser satisfacion

La timidèz, que condena.

Por quitarte à ti el aplauso,

Que el Cielo esta gloria pierda?

...

Pues, señora, llegó el tiempo

De persuadiros la enmienda:

Y que hagáis restituyendo,

Principio à vna vida nueva.

Salgan à la luz del Mundo

Los conceptos, que de ella

A tu diligencia, ocultan 
Los huecos de tus Gavetas.

...

Y assi, señora, podrán

Quedar de ti satisfechas

Las providencias del Cielo,

Y las quexas de las tierra.

No aguardes à que indignados

Ya contra tu resistencia,

Con el nombre de Tyrana,

Te publiquen todos Guerra. (Obras poéticas)

Una vez tiene noticia de la publicación de sus obras, Mallén escribe unas décimas alabando el hecho y la protección recibida:
Mas puede ser tu consuelo
El refugio, que han tomado
Tus Obras, para sagrado
Del mas vengativo anhelo
Ya no puede en el recelo
Hallar temor tu fortuna,
Pues adversidad ninguna
Podrà atreverse à quien es
Oy tropheo de los pies
De la Duquesa de Ossuna. (Obras poéticas)

Poco sabemos de este personaje ya que no aparece en las bibliografías que hemos investigado. Como el poema de Mallén se imprime en Sevilla, nos parece lógico incorporarlo al ambiente de literatos andaluces y pensar que posiblemente sea pariente de Ana Caro Mallén de Soto ${ }^{17}$. Lo único que hemos encontrado de él es un poema de 26 octavas escrito en acróstico en honor de Felipe V, "Cordiales afectos que en ecos demonstrativos, ofrece la lealtad, en el feliz sucesso de la Restitucion de Madrid, por las Armas de nuestro Catholico Rey y Señor Don Phelipe V el Animoso y Fuga vergonzosa de los enemigos de su corona el dia 4 de diciembre año de 1710». Por el mismo, vemos que defendía el derecho del rey Borbón al trono en contra de Carlos III, ya que la lucha de 1710 corresponde al triunfal retorno de Felipe $\mathrm{V}$ a Madrid el 3 de diciembre de ese mismo año (Kamen, p. 76).

17. En su Varones Insignes en letras naturales de la ilustrísima ciudad de Sevilla, Rodrigo Caro aclama a su posible pariente Ana Caro como «insigne poeta»; véase Amy Kaminsky, Water Lilies, Minneapolis, University of Minnesota, 1995, pp. 202-205. 
Junto con el poema de Mallén en el paratexto de las Obras poéticas se encuentran otros dos sonetos en alabanza de la autora de anónimos «apasionados» más uno en elogio de su «heroyca pluma» por D. Gabriel Gilberto Cavalleri y Villalobos, a quien tampoco hemos logrado identificar. Quien mejor aboga por nuestra poeta es el mismísimo Torres Villarroel, al firmar la "Aprobación" que aparece en el libro en Madrid, con las siguientes palabras:

No he conocido Poesias más sanas que las que dicta esta Decima Musa. El afan coplico, en los mas animos engendra mètricas congojas y musicas obstrucciones; pocos son los Versificantes bien humorados ... Y asseguro a $\mathrm{V}$. md. que quedo curioso por conocer a tan graciosa capacidad; y mientras me concede esta fortuna mi christiano deseo, pido de gracia se me dè un impreso, para venerar en sus Obras sus talentos. (Obras poéticas)

Las alabanzas de Torres Villareal al poemario de Guerra contradicen la opinión de los críticos más recientes; la del hispanista décimonónico George Ticknor, cuyos estudios sentaron la base de la historia literaria española en las aulas universitarias norteamericanas, no puede ser más negativa, declarando «miserables» los versos de la poeta ${ }^{18}$. El profesor Palacios, quien, como hemos visto, la incluye en su estudio sobre la mujer y las letras del siglo XVIII, plantea una recensión mucho más matizada, aunque acaba con un dictamen desfavorable:

Emplea un tono gracioso y desenfadado, inusual en la literatura femenina de este tipo [...] es una rimadora fácil de romances, décimas y sonetos, con una musicalidad unas veces en exceso violenta y otras poco acertada. Practica un denso estilo barroco, en el que caben los juegos de palabras, los calambures, una cierta oscuridad en consonancia con sus venerados Góngora y Quevedo (La mujer y las letras, p. 136).

Nos parece que la crítica negativa, que creemos refleja más bien la aversión moderna por la supuesta intranscendencia y pobreza de invención de la poesía de la primera mitad del siglo, no toma en cuenta la incertidumbre y las múltiples crisis filosóficas, económicas, y políticas por las que pasaba la sociedad española. Las tumultuosas décadas que marcan los cambios

18. George Ticknor, History of Spanish Literature, Vol. III, Londres, Truebner, 1863, p. 247, n. 20. Ticknor donó su copia del libro a la biblioteca pública de la ciudad de Boston; es la única copia del poemario que hemos podido encontrar en los Estados Unidos. 
estilísticos de la poesía encierran a su vez una fase intensiva de autocrítica y reforma que desembocará en la Ilustración. No cabe duda de que el papel de la mujer, tanto de escritora como lectora, formaba parte del cuestionamiento ideológico de la época; la Defensa de la mujer de Feijoo, por ejemplo, se divulgó rápidamente en Francia y a fines de la centuria se encontraba ya traducida al inglés, italiano y portugués ${ }^{19}$. En los círculos más alejados de la corte, no fueron únicamente las damas aristocráticas quienes contribuyeron al mundo literario; según nos asegura Mónica Bolufer:

Por otra parte, las escritoras de la época, que pertenecían en muchos casos a medios sociales distintos ... utilizaron también en su favor algunos de los nuevos espacios y géneros literarios y de los argumentos del siglo sobre la deseable extensión de la cultura escrita más allá de los reducidos círculos eruditos como estrategias para autorizar su escritura literaria y, en ocasiones, reclamar su pertenencia a esa «república de las letras» ${ }^{20}$.

Ciertamente, la contribución de la mujer al mundo literario no se limitaba a su participación en las tertulias o academias, sino que sus obras circulaban impresas ${ }^{21}$. En el caso del poemario de Guerra, sabemos que se mencionó, sin el nombre de la autora, en La Gaceta de Madrid el 30 de octubre de 1725 en el siguiente anuncio: "Libro nuevo. Obra poética de diferentes assumptos ha escrito una Señora de Andalucia. Se vende en casa de Fernando Monge, Mercader de libros» ${ }^{22}$.

La temprana publicación del poemario y el hecho de que fuera tan alabado en su época merece, por tanto, un estudio más a fondo y detallado. Un repaso del contenido del poemario nos manifiesta la gran variedad de temas a los que se dedica. Aunque incluye varios poemas de tema religioso y hagiográfico como el romance «Al martyrio de S. Justo y Pastor» (pp. 1-13)

19. Para un análisis de la "cuestión de la mujer» en el s. XVIII, véase el primer capítulo de Theresa Ann Smith, The Emerging Female Citizen: Gender and Enlightenment in Spain, Berkeley, CA: University of California Press, 2006.

20. Mónica Bolufer Peruga, «Escritura femenina y publicación en el siglo XVIII: de la expresión personal a la «República de las letras», Biblioteca Virtual Universal, http://www. biblioteca.org.ar/libros/134541.pdf.. Véase también su Mujeres e Ilustración. La construcción de la feminidad en la España del siglo XVIII, Valencia, Institució Alfons el Magnànim, 1998.

21. Bolufer constata que se publicaron más de 160 obras en el siglo y aun cuando la cifra no resulta "espectacular», nota que habríanse de tomar en cuenta las muchas publicaciones de poemas y otros escritos salidos en la prensa periódica («Escritura femenina»).

22. Agradecemos al profesor Jean-Marc Buigues la información del anuncio en La Gaceta, que presentó en el coloquio internacional «El libro de poesía (1650-1750): Del texto al lector» organizado por él y el profesor Pedro Ruiz Pérez en la Facultad de Filosofía y Letras, Universidad de Córdoba, del 15 al 17 de febrero de 2010. 
y las décimas «A una imagen de Christo crucificado» (pp. 45-48), y otros amorosos hiperbólicos, como las octavas «A la memoria de los lamentos con que Roma se quexaba, quando ardia mas entre las inhumanidades de Neron, que entre los rigores del fuego, à cuyo exemplo se quexa vn enamorado" (pp. 44-45), es obvio que se inclina más por la poesía circunstancial. Así, el poemario recoge el romance, los sonetos y los jeroglíficos compuestos por Guerra con motivo de las exequias del rey Luis I (pp. 60-77) ${ }^{23}$. El romance exalta la ascensión al trono de Felipe $\mathrm{V}$ y el fugaz reino de su hijo, mientras que los sonetos van puestos en boca de Europa, América, Asia y África, las cuatro estatuas que representan las cuatro partes del mundo en el túmulo erigido en la catedral de Cádiz; les siguen varios jeroglíficos que escribe en octavas para adornar el templo (pp. 77-82). No sólo es evidente que la comunidad gaditana acepta de lleno el talento poético de la escritora, sino que vemos en estas obras su deseo de compartir el momento histórico, participando plenamente en el sentimiento elegíaco del pueblo por la abdicación del primer rey Borbón y la inesperada muerte del segundo.

Tal como sugiere Palacios, algunos de sus poemas revelan el ambiente de las tertulias literarias, pues bien podrían responder a la temática exigida por las mismas. Un poema, por ejemplo, se titula «Presidiendo de repente un Certamen, a instancias de un caballero su apasionado» (p. 54-58) en el que menciona, como veremos en otros, a un conocido suyo quien le exige, a un don Diego de Landa ${ }^{24}$. Entre sus poemas, hay algunos que presumen ser escritos por los conocidos de la autora, aunque también podrían considerarse un juego retórico. En efecto, uno se titula « $V n$ dia que llovia, pidio à la Poetisa este Romance Don Joseph de Barrios, por los siguientes versos» (pp. 13-15) en el que Barrios le celebra jocosamente su romance al martirio de los santos Justo y Pastor, con lo cual ella responde "Por no aver estado en casa quando llegò este papel, respondiò al otro dia. Carta» (pp. 15$21)^{25}$. Otro de sus poemas es una "Carta en que responde à su hermano quien le diò noticia de tenerse por cierto; se avia entrado en Religion Don Eugenio Gerardo» (pp. 21-28) ${ }^{26}$. Aclara en sus versos la imposibilidad de

23. El rey Luis I, hijo de Felipe V, murió a los siete meses de abdicar el padre en 1724, quien volvió a asumir la corona ese mismo año (Kamen, pp. 147-150).

24. El personaje mencionado no debe confundirse con el obispo franciscano de Yucatán (1524-1579).

25. Joseph de Barrios, cargador de Indias, regaló el retablo central de la Iglesia del Convento de las Concepcionistas de la Puerta de Santa María; muerto en 1771, se encuentra enterrado en el templo.

26. Eugenio Gerardo Lobo (1679-1750), a veces llamado El Capitán Coplero por sus críticos, a quien aparentemente admiró la poeta. 
que el poeta Eugenio Gerardo Lobo, quien fuera teniente y gobernador militar de Barcelona, hubiese tomado ese camino: «De cuyas noticias vagas / me escriviràs la evidencia; / Y dime, qual feliz Templo / Tan nueva reliquia encierra». Termina por decirle que "De viaje la caridad, / aquí cae, allí tropieza,/ sin que en grandes, ni pequeños / aya vn alma, que la tenga».

A raíz de ese poema, incluye otro titulado « $V n$ cavallero Rector de cierta Universidad la escriviò los siguientes Versos en vista de la Carta antecedente»:

Doemonium habes, de Christo

Dixeron los Fariseos;

$\mathrm{Y}$ doemonium habes, digo

Yo, señora, de tus Versos.

No lo digo de ti,

Sino lo digo de ellos;

Y si de ti, por ser tuyos,

Lo digo de Dios dixeron.

...

Son, pues, tus versos agudos,

Doctos, profundos, discretos;

Y son tuyos, que es lo mas,

Con que lo demás es menos. (p. 29)

A los cuales versos ella responde a continuación, acabando con la pregunta retórica:
¿Donde aprendiste la rara,
artificiosa, exquisita
nunca practicada ciencia
muchas veces peregrina
de convertir (a pesar de
enemistad tan reñida)
en suma discrecion tuya
la suma ignorancia mia? (pp. 30-32)

La relación juguetona que sostiene con el rector le permite enviar otro poema, titulado «En ocasion que padecia este mismo sugeto un grano ò apostema en el orificio y le curaba un Cirujano llamado Corro, embiò à saber de su enfermedad, en los siguientes Versos»:

Perdoname, por tu mal,

$\mathrm{Vn}$ estilo tan grosero,

Quando te mereces el

Mas agudo, en mi concepto. 
TERESA GUERRA, POETA ENTRE EL BARROCO Y LA ILUSTRACIÓN

Se ha dicho, que padecias

Vn naufragio en el estrecho;

$\mathrm{Y}$ à vanderas desplegadas,

Caminabas con mal viento.

Y que el baxèl les decía:

Ya Corro, ya me estoy quedo,

A los navegantes, sea

La borrasca para ellos.

...

Pero por mucho, que corra

Tu accidente, es mi deseo

Tan agil, que de los dos,

Serà tu mal el trasero.

...

Ponte en pie, por fin, y mira,

Que el mal te viene siguiendo:

No quiera Dios, que por ti

Se diga: Puto el postrero. (pp. 32-36)

El profesor Palacios ha criticado la abierta vulgaridad del poema, sin adentrar en los pormenores del mismo, al señalar que la poeta desvía su interés «hacia motivos chuscos y aun groseros» (p. 136). Pero es precisamente la facilidad con que la escritora se acerca a estos tópicos la manera más acertada de comprobar la trayectoria de la liberación que culminará en el llamado libertinaje de la segunda mitad del siglo. Si, como decía Marcelino Menéndez y Pelayo, la poesía licenciosa representa la llaga secreta de la literatura del siglo XVIII, Mario di Pinto nos hace ver que esa misma llaga no es la transgresión del lenguaje, que incluso ya había formado parte de la literatura anterior del Siglo de Oro ${ }^{27}$. Más bien, se trata de la liberalización, ya sea a través del discurso científico o, como vemos en esta pequeña muestra, de la discursividad del cuerpo. En efecto, el que fuera una mujer quien asumiera tal libertad a principios del siglo nos lleva a cuestionar el papel de la mujer justamente en ese momento, pues denota una desenvoltura que seguirá manifestándose a través de lo que Guillermo Carnero ha designado «la cara oscura» de la Ilustración ${ }^{28}$.

27.Véase Manuel Fernández Nieto, «El festín de amor en la literatura dieciochesca», coordinadores Javier Huerta Calvo y Emilio Palacios Fernández, Al margen de la ilustración. Cultura popular, arte y literatura en la España del siglo XVIII, Amsterdam; Atlanta, GA.: Rodopi, 1998, pp. 171-206; y Mario di Pinto, «L'osceno borguese nota sulla letteratura erotica spagnola nel Settecento», en I codici della transgressività in area ispanica, Verona, 1980.

28. Guillermo Carnero, La cara oscura del Siglo de las Luces, Madrid: Fundación Juan 
No es tan sólo el aspecto erótico el que se proyecta en las obras de Guerra. El poemario acaba con un poema llamado "Crisis sobre vn Sermon del Principe de los Apostoles San Pedro, que se predicò en verso en la Ciudad de Medina Sidonia» (pp. 106-137). Por medio de su «respuesta de vna Carta, en que iba incluso / Escrita en verso, porque vaya al vso", la poeta reprueba a un tal cura Cobo la aprobación del sermón:
De cierto Padre Cobo es la Censura, que prueba su Passion al Padre Cura Yo no conozco al dicho Padre Cobo Sino es pariente de Gerardo Lobo. Y lo debe de ser, según la pía inclinacion a verbo Poesía. ... Los versos en los psalmos son sagrados los versos en sermones, reprobados. ... No vayan los Sermones desgreńados; Pero tampoco vayan profanados. ... Que el Sermon està docto, no lo niego; Pero por sus Coplitas de èl reniego. . . . Si en esto porfiàra vna Muger, Dixera, sin andar con alfileres, Que por fin era cosa de Mugeres. Pero que tu lo digas, y redigas! Mereces que te cuelgen treinta higas ... A las Ave Marias nos volvamos, Porque con algo bueno concluyamos. Ponerse las aquí quiere mi musa, Porque à el fin de el Sermon assi se ussa. ...

Que una mujer también decidiera criticar lo que parece ser un sermón en rima y que se le publicara la crítica de un cura, por más que pudiera ser una invención de la propia poeta, nos parece un indicio más del cambio epistémico de una época histórica a otra. Ciertamente, Theresa Ann Smith nos recuerda la singular importancia de la Defensa de Feijoo en redimir la capacidad intelectual de la mujer (p. 41). No hace menos el poema en reivindicar la gracia y el buen juicio de su autora.

\footnotetext{
March/Cátedra, 1983. Véase también Iris Zavala, «El libertinaje: la hora de la libertad» en Huerta Calvo y Palacios Fernández, op. cit., pp. 169-184. Zavala habla del «lado escondido, subversivo del siglo XVIII español, como parte de la cara oculta del setecientos» en su artículo "Viaje a la cara oculta del setecientos», Nueva Revista de Filología Hispánica, 33, 1984, pp. 4-33.
} 
Nos quedamos, sin embargo, con la incógnita de Teresa Guerra y su poemario. Sin ninguna otra muestra de su escritura, sin siquiera saber dónde ni cómo viviría la poeta, sólo podemos especular acerca de su significado histórico y literario. No sería improbable que el dialogismo de la estructura formal de los poemas que van dirigidos a lectores específicos y los que dicen ser escritos por sus amigos constituyan una expresión literaria del famoso «chichisbeo» de principios del siglo XVIII, que según Carmen Martín Gaite, es la conversación íntima entre una mujer casada y un amigo (llamado el "estrecho») ${ }^{29}$. Este cortejo, según Fernández Nieto, da lugar a un protocolo de reglas de relación entre los sexos que recuerda el «cicisveo» italiano en el que se sorteaban las parejas a fin de año, intercambiándose poemas («El festín», p. 190). La extensión de estas costumbres curiosas se manifiesta en el cortejo amoroso por correspondencia de la novela de la escritora inglesa Mary Davys, Familiar Letters, Betwixt a Gentleman and a Lady [Cartas familiares entre un caballero y una dama] publicada justamente en $1725^{30}$. El tema principal de la misma es la lucha contra las desigualdades sociales existentes entre los sexos, planteándose la posibilidad a la mujer de vivir célibe y renunciar al amor. Si bien en esta novela, es el temor por perder su libre albedrío en el matrimonio lo que revela la vulnerabilidad de las mujeres, las relaciones con los hombres se mitigan por medio de una amistad que, cuando menos, se adelanta al libertinaje dieciochesco seńalado por Carnero y Zavala. No debemos sorprendernos, por tanto, que el «chichisbeo» fuera defendido por el poeta Lobo, quien dedica unas décimas a la práctica:

$$
\begin{aligned}
& \text { Es, Señora, el Chichisbeo } \\
& \text { Vna inmutable atencion, } \\
& \text { Donde nace la ambicion } \\
& \text { Estrangera del desseo. } \\
& \text { Exercicio sin empleo, } \\
& \text { Vagante llama sin lumbre, } \\
& \text { Vna elevacion sin cumbre } \\
& \text { Vn afán sin inquietud, } \\
& \text { Que no siendo esclavitud, } \\
& \text { Es la mayor servidumbre }{ }^{31} \text {. }
\end{aligned}
$$

29. Carmen Martín Gaite, Usos amorosos del dieciocho en España, Madrid, Siglo XXI, 1972

30. María Jesús Lorenzo Modia, Literatura femenina inglesa del siglo XVIII, A Coruña, Universidade da Coruńa, 1998.

31. Obra poéticas, del Excmo. señor don Eugenio Gerardo Lobo, Pamplona, 1725. 
Tampoco nos sorprende que esta práctica, la cual, sin embargo, fue criticada también por Lobo en algunos poemas, fuera reprobada por ser una delictiva costumbre extranjera ${ }^{32}$. No obstante, para Martín Gaite, la moda del cortejo representa «el germen de una actitud distinta con respecto al papel de la mujer en la sociedad y permite entender los albores del malestar matrimonial» ${ }^{33}$. Tal como sugiere María Victoria López Cordón, el modelo de sociabilidad de la corte, de las academias y hasta de las tertulias en casas particulares no sólo permitió que las mujeres tomaran una parte mucho más activa en la sociedad, sino que ayudó a derrocar la inconexión tanto intelectual como física que mantenían los sexos en público ${ }^{34}$. Hemos visto que la experiencia literaria femenina se realiza en diversos ámbitos y niveles sociales, desde la corte madrileña hasta las villas andaluzas, abriéndose paso la mujer en el nuevo mundo intelectual y afectivo de la Ilustración. Es así que las tempranas obras poéticas de Teresa Guerra nos permiten enfrentar la compleja dualidad que perdura después del período barroco entre la razón y el erotismo, enfocando a la vez la significación del género en la aspiración a la libertad individual.

32. Francisco Xavier de Corral, Consejo familiar ... por el chichisbeo que defendio Don Eugenio Gerardo Lobo. Madrid, 1717.

33. «Las raíces del feminismo», entrevista con la autora en El Pais, $1^{\circ}$ abril, 1981, http:// www.elpais.com/articulo/cultura/MARTIN_GAITE/_CARMEN/raices/feminismo/espanol/ Carmen/Martin/Gaite/elpepicul/19810401elpepicul_14/Tes.

34. María Victoria López Cordón, «Women in Society in Eighteenth-Century Spain: Models of Sociability", Eve's Enlightenment: Women's Experience in Spain and Spanish America, 1726-1839, coord. Catherine M. Jaffe y Elizabeth Franklin Lewis, Baton Rouge, LA., Louisiana State University Press, 2009. 